\title{
Problems and Solutions in Laboratory Testing for Hemophilia
}

Emmanuel J. Favaloro, PhD, FFSc (RCPA) ${ }^{1}$ Piet Meijer, $\mathrm{PhD}^{2}$ lan Jennings, $\mathrm{PhD}^{3}$ John Sioufi ${ }^{4}$

Roslyn A. Bonar, BSc ${ }^{4}$ Dianne P. Kitchen, FIBMS ${ }^{3}$ Geoffrey Kershaw, FAIMS ${ }^{5}$ Giuseppe Lippi, MD ${ }^{6}$

\footnotetext{
1 Department of Haematology, Institute of Clinical Pathology and Medical Research (ICPMR), Pathology West, Westmead Hospital, Westmead, New South Wales, Australia

2 ECAT Foundation, Dobbeweg 1, Voorschoten, The Netherlands

3 NEQAS UK Coagulation, Sheffield, United Kingdom

${ }^{4}$ RCPAQAP Haematology, St Leonards, New South Wales, Australia

5 Institute of Haematology, Royal Prince Alfred Hospital, Camperdown,

New South Wales, Australia

${ }^{6}$ Department of Pathology and Laboratory Medicine, Laboratory of Clinical Chemistry and Hematology, Academic Hospital of Parma,

Parma, Italy
}

Semin Thromb Hemost 2014;40:135.

\begin{abstract}
Address for correspondence Emmanuel J. Favaloro, PhD, FFSC (RCPA), Department of Haematology, Institute of Clinical Pathology and Medical Research (ICPMR), Pathology West, Westmead Hospital, Westmead, New South Wales 2145, Australia.
\end{abstract}

\section{ERRATUM}

The above article (Volume 39, Number 7, pp. 816-833) listed incorrect affiliation information for the author Dianne P. Kitchen. She is presently affiliated to NEQAS UK Coagulation, Sheffield, United Kingdom, as shown in the above details.

Issue Theme Old and New Challenges in Hemophilia Management; Guest Editors, Antonio Coppola, MD, Annarita Tagliaferri, MD, and Massimo Franchini, MD.
Copyright $\odot 2014$ by Thieme Medical Publishers, Inc., 333 Seventh Avenue, New 10.1055/s-0033-1360721. York, NY 10001, USA. Tel: +1(212) 584-4662. 